\title{
Natural Resources in the Theory of Production: The Georgescu-Roegen/Daly versus Solow/Stiglitz Controversy
}

\author{
Quentin Couix ${ }^{\mathrm{a}}$ \\ a Centre d'économie de la Sorbonne (CES), Université Paris 1 Panthéon-Sorbonne, Paris, \\ France. https://orcid.org/0000-0001-7789-0708
}

\begin{abstract}
ARTICLE HISTORY
Compiled July 1, 2021

Abstract

This paper provides a theoretical and methodological account of an important controversy between neoclassical resource economics and ecological economics from the early 1970s to the end of the 1990s. It shows that the assumption of unbounded resource productivity in the work of Solow and Stiglitz-and the related concepts of substitution and technical progress-rest on a model-based methodology. On the other hand, Georgescu-Roegen's assumption of thermodynamic limits to production, later revived by Daly, comes from a methodology of interdisciplinary consistency. I conclude that neither side provided a definitive proof of its own claim because both face important conceptual issues.
\end{abstract}

\section{KEYWORDS}

Nicholas Georgescu-Roegen; Robert Solow; Joseph Stiglitz; natural resources; theory of production

\section{JEL CLASSIFICATION}

B22; Q32; Q57

\section{Introduction}

Modern economic thought on natural resources issues went through an important episode in the 1970: 1 . One of the events that triggered this was the publication of the report The Limits to Growth (Meadows et al. 1972), which suggested that continued economic growth could lead to ecological collapse due to resource depletion and the accumulation of pollution. Growth economists, such as Robert Solow (1973, 1974a b) and Joseph Stiglitz (1974), strongly criticised the report on both a methodological and theoretical basis. In parallel, they proposed their own approaches based on the neoclassical growth framework initiated by Solow (1956). This framework had become very popular in the 1960s (Boianovsky and Hoover 2009). Among important assumptions, their models incorporated the idea that the productivity of resources could be increased

CONTACT Quentin Couix. Email: quentin.couix@univ-paris1.fr. The Version of Record of this manuscript has been published and is available in The European Journal of the History of Economic Thought, 2019, https://www.tandfonline.com/doi/10.1080/09672567.2019.1679210

${ }^{1}$ The preoccupations regarding the depletion of natural resources had been discussed in economics before this period. See for instance Missemer (2017a). Even though they partially relied on these earlier works, the approaches that emerged in the 1970s rested on new concepts and tools that considerably reframed questions. 
indefinitely thanks to the substitution of capital to resources or technical progress. This led to the conclusion that constant or even growing consumption could be achieved in the long run, and these contributions laid the foundations of a new branch of growth theory, here labelled as "neoclassical resource economics"2

But almost at the same time, another research program had emerged inside the economic community which was closer to the views of the report The Limits to Growth. It was initiated in particular by Nicholas Georgescu-Roegen (1971), who had become more and more critical of neoclassical theory after contributing to it $t^{3}$ He proposed a reorientation of economic theory based on references to thermodynamics, and placing environmental issues at the heart of its preoccupations. This naturally led him to take part in the debate on the limits to growth (Levallois 2010). He criticised Solow's and Stiglitz's works on exhaustible resources (1975 1979), especially their representation of production with unbounded resource productivity. Conversely, he argued that production must abide by the laws of thermodynamics and that this sets limits to substitution and technical progress.

This criticism was revived by Herman Daly almost twenty years later in an article called "Georgescu-Roegen versus Solow/Stiglitz" (1997a). As a former student, Daly had been much influenced by Georgescu-Roegent Then, he played an important role in the institutionalisation of the new school of "ecological economics", where he promoted the ideas of his mentor. In fact, his article of 1997 was part of the issue of Ecological Economics dedicated to Georgescu-Roegen, who had died in 1994. It generated one of the most direct confrontations between neoclassical resource economists and ecological economists, which shows how much the underlying issues are constitutive of this opposition. Hence, studying this controversy, from the 1970s to the 1990s is a good opportunity to better understand the fundamental divergences between these two approaches. The purpose of the present paper is to give a detailed account of it, with a focus on the theoretical and methodological issues at stak $\oint^{5}$

This investigation complements the current literature on the history of environmental issues in economic thought. The period from the 1970s to the 1990s has been the subject of historical accounts by practitioners from both neoclassical resource economics (Pearce 2002) and ecological economics (Spash 1999, Røpke 2004). While they mention the authors considered here as important contributors, they have remained at a quite general level of understanding. This does not enable us to grasp the more technical issues at stake in the development of both fields and in their confrontation ${ }^{6}$ The present contribution intends to improve this understanding through a complete investigation of

\footnotetext{
${ }^{2}$ I use this label in order to be more precise than the usual one of "natural resource economics" found in literature. This choice underlines the continuity with the neoclassical theories of production and growth and clearly distinguish it from ecological economics.

${ }^{3}$ Kenneth Boulding (1966) is another important early contributor of this new approach, and he shares a similar intellectual trajectory.

${ }^{4}$ Despite this influence, Daly and Georgescu-Roegen did not always agree with each other. The main point of contention between them was question of the "steady state" (Daly 1974, Georgescu-Roegen 1977). I briefly discuss this problem again in section 4

${ }^{5}$ By "theory" I mean the concepts that constitute the intellectual framework through which economists conceive their objects of study. In particular, I distinguish them from "models" as purely mathematical systems. In this context, "methodology" is primarily understood as the way concepts are built, and how they articulate with models.

${ }^{6}$ In a still general perspective, Pottier 2014 chap. 2) provides some insights on the technical issues raised by early works in natural resource economics. A more specific contribution on the influence of John Rawls and Harold Hotelling on Solow is provided by Erreygers (2009). There also exists an important body of literature specifically dedicated to Georgescu-Roegen's conception of environmental issues (Gowdy and Mesner 1998 Bobulescu 2012, 2013, 2015 Missemer 2017b). While it provides insights on some aspects of the present controversy, no contribution takes it as its central subject.
} 
the thread that leads from the early works of Solow and Stiglitz, and their criticism by Georgescu-Roegen, to the debate of 1997. This especially provides an illustration of the two facets of the process of "identity formation" in ecological economics suggested by Røpke (2005): the determination of the theoretical roots of the field through the discussion of precursors; and the clarification of the divergences with the competing approach of neoclassical resource economics.

The article is organised in three sections. Section 2 shows how the assumption of unbounded resource productivity was integrated in Solow's and Stiglitz's models under the form of substitution or technical progress. I characterise the methodology underpinning this approach as model-based, and I examine the conceptual issues it raises. Section 3 introduces Georgescu-Roegen's thermodynamic approach of the economic process. I reconstruct and critically examine his criticism of Solow's and Stiglitz's works, focusing on the idea of thermodynamic limits and its underlying methodology of interdisciplinary consistency. Finally, section 4 shows that the debate of 1997 rests on the same theoretical and methodological oppositions, and highlights in particular the issues related to the conceptual integration of physical and economic concepts.

\section{Solow, Stiglitz, and the Origins of Neoclassical Resource Economics}

As Robert Solow expressed in his Richard T. Ely lecture in December 1973, it is the report The Limits to Growth (Meadows et al. 1972) that sparked his interest in natural resources:

About a year ago, having seen several of those respectable committee reports on the advancing scarcity of materials in the United States and the world, and having, like everyone else, been suckered into reading The Limits to Growth, I decided I ought to find out what economic theory has to say about the problems connected with exhaustible resources. (Solow 1974a, 1-2)

His model was presented in a "Symposium on the Economics of Exhaustible Resources", and later published in a special issue of The Review of Economic Studies (1974b). Together with Stiglitz (1974) in the same issue, his article had an important influence on later works. These papers shared a similar framework and laid the foundations of the neoclassical analysis of growth with exhaustible resources, or "neoclassical resource economics'?

\subsection{Growth Models and Unbounded Resource Productivity}

The general framework is that of Solow's neoclassical growth model (1956). Among the key features of this model is the notion of "production function", relating the level of output $Q$ to the level of the factors of production and the time variable $t$. While traditionally only aggregate capital $K$ and labour $L$ were considered as relevant production factors, neoclassical resource economists introduced a variable $R$ representing the flow

\footnotetext{
${ }^{7}$ Still in the same issue, Dasgupta and Heal $(1974)$ provided another important contribution, which led some authors to speak of the Dasgupta-Heal-Solow-Stiglitz (DHSS) model (Benchekroun and Withagen 2011). I do not consider the work of Dasgupta and Heal in the present paper for two reasons: first, they did not participate actively in the subsequent controversy with ecological economists; second, their model relies on a utilitarian norm of intergenerational distribution that would require the introduction of additional formal aspects but would not contribute to a better understanding of the controversy.
} 
of resources in the production function:

$$
Q=F(K, R, L, t)
$$

The notion of "resource" itself is illustrated either by energy sources, such as oil or coal, or by minerals, such as copper or phosphate minerals. These resources are considered exhaustible and taken from a finite stock $S_{0}$. Time is involved in the production function to account for "exogenous technical progress", defined most generally as variations of output that are not attributable to variations of the factors of production.

The evolution of capital and population is similar to traditional growth theory: net investment is equal to total production minus consumption, and population grows at an exogenous rate. Given this framework, the question addressed by both Solow and Stiglitz is to know whether certain intergenerational levels of consumption can be achieved or not. However, they consider slightly different configurations of this problem.

Solow (1974b) studies the case of a constant population and a constant consumption per head across generations, which he links to the notion of justice in the work of John Rawl 8 Then, he argues that some assumptions have to be made on the production function for the problem not to be trivial:

For the problem to be interesting and substantial, $R$ must enter in a certain way. For example, if production is possible without natural resources, then they introduce no new element. [...] On the other hand, if the average product of resources is bounded, then only a finite amount of output can ever be produced from the finite pool of resources; and the only level of aggregate consumption maintainable for infinite time is zero.

The interesting case is one in which $R=0$ entails $Q=0$, but the average product of $R$ has no upper bound. (Solow 1974b, 34)

Here, Solow introduces the assumption of "unbounded resource productivity" which postulates that output is not absolutely limited by the flow of resources. As he acknowledges, this assumption is crucial if one looks for levels of consumption that can be maintained indefinitely. If it does not hold, consumption must necessarily decline at some point. Moreover, according to him, this justifies one to use a Cobb-Douglas production function of the form:

$$
Q=K^{\alpha} R^{\beta} L^{\gamma}, \alpha+\beta+\gamma=1
$$

In this case, it is the "substitutability" between aggregate capital and resources that ensures unbounded resource productivity 9 . Under these assumptions, Solow demonstrates that a strictly positive level of consumption can be maintained if and only if the

\footnotetext{
${ }^{8}$ See Erreygers $(2009)$ for a discussion of this aspect.

${ }^{9}$ Formally, this can be seen by rewriting the production function as: $\frac{Q}{R}=\left(\frac{K}{R}\right)^{\alpha}\left(\frac{L}{R}\right)^{\gamma}$. If $R$ and $L$ are constant, the productivity of resources on the left may be as large as one wishes, provided $K$ is sufficiently great.
} 
output elasticity of capital is greater than that of resources ${ }^{10}$

$$
\alpha>\beta
$$

The path that realises this constant consumption per head has monotonically increasing capital stock and decreasing resource flow. Therefore, the possibilities of substitution inherent in the Cobb-Douglas production function, and the assumption of unbounded resource productivity it encapsulates, play a central role in this result.

On his side, Stiglitz (1974) examines the case of a population growing at a constant rate $n$, with a Cobb-Douglas production function and exogenous technical progress at a constant rate $\lambda$, such that:

$$
Q=e^{\lambda t} K^{\alpha} R^{\beta} L^{\gamma}, \alpha+\beta+\gamma=1
$$

In this framework, he shows that a constant consumption per head can be maintained if and only if ${ }^{11}$

$$
n<\frac{\lambda}{\beta}
$$

This condition is interpreted as the need for "resource augmenting technical progress" to be greater than the rate of demographic growth 12 Rather than capital substituting for resources, it is now technical progress that plays the central role in compensating the decreasing flow of resources. But, this is just another way of ensuring the same assumption of unbounded resource productivity ${ }^{13}$

Hence, unbounded resource productivity under the form of technical progress or substitutability is crucial to overcome the scarcity of resources in these models. As Stiglitz himself summarises :

The fact that there is a limited amount of natural resources and natural resources are necessary for production does not necessarily imply that the economy must eventually

${ }^{10}$ Solow's demonstration relies on the minimisation of $\int_{0}^{\infty} R(t) d t$ under the constraints of capital accumulation. This is summarised by a differential system with two equations:

$$
\dot{K}=Q-C \text { and } \frac{\dot{F}_{R}}{F_{R}}=F_{K}
$$

where $F_{R}$ and $F_{K}$, are the marginal productivities of resources and capital. Solow shows that there exists a solution of this system that consumes less than the total stock of resources if and only if inequality 3 is satisfied.

${ }^{11}$ Stiglitz's equations of evolution are similar to that obtained by Solow, except that they introduce constant growth rates of technical progress and population. In fact, Stiglitz establishes a more general condition for aggregate consumption to grow at a constant rate $g$ :

$$
g<\frac{\lambda+\gamma n}{1-\alpha}
$$

Setting $g=n$ in this inequality yields condition 5 .

${ }^{12}$ Rewriting the production function as $Q=K^{\alpha}\left(\operatorname{Re}{ }^{\frac{\lambda}{\beta} t}\right)^{\beta} L^{\gamma}$ we see that $\frac{\lambda}{\beta}$ can be considered as the rate at which technical progress improves the level of resources, which justifies the label "resource augmenting technical progress".

${ }^{13}$ In the second part of the same paper, Stiglitz studies another model based on a similar production function. Instead of constant growth, he uses a utilitarian norm of intergenerational distribution, which consists of maximising the sum of discounted utilities across generations. Once again, technical progress plays a central role in escaping the scarcity of resources in this model: the asymptotic growth rate of consumption per head is positive if and only if resource augmenting technical progress is greater than the discount rate. 
stagnate and then decline. Two offsetting forces have been identified: technical change and capital accumulation. Even with no technical change, capital accumulation can offset the effects of the declining inputs of natural resources, so long as capital is 'more important' than natural resources, i.e. the share of capital is greater than that of natural resources. With technical change, at any positive rate, we can easily find paths along which aggregate output does not decline. (Stiglitz 1974, 130-131)

\subsection{A Model-Based Methodology}

The work of Solow and Stiglitz gave neoclassical resource economics its most important features. A whole literature was built on this framework, to which Solow and Stiglitz made other important contributions ${ }^{14}$ Along this trend, the assumption of unbounded resource productivity, and the notions of substitution and technical progress, kept a central role. Here, I investigate the foundations of this assumption.

For this purpose, it is necessary to understand how substitution and technical progress are conceived in neoclassical resource economics. In analytical contributions (Solow 1974b: Stiglitz 1974), these notions primarily appear as mathematical properties of production functions. On the one hand, substitution describes the possibility of increasing the productivity of resources $\frac{Q}{R}$ by increasing the level of capital $K$. On the other hand, technical progress is concentrated in the multiplier $e^{\lambda t}$. Its determinants are not specified and it is assumed to be independent of the factors of production. This endows them with well-identified mathematical meanings.

However, these mathematical meanings do not give any conceptual substance to these notions. In fact, there are very few conceptual elaborations of them in the work of Solow and Stiglitz, and they raise some important issues. To start with, three different mechanisms can be identified to illustrate the notion of substitutability. First, substitution may occur between resources-for instance from oil to coal thanks to coal-liquefaction technology (Solow 1974a, 5), or from fossil fuels to "backstop technologies", such as nuclear fusion or solar energy (Solow 1974a, 11). Second, substitution can mean a change in the composition of output toward less resource-intensive goods (Solow 1978, 6). And finally, it can denote a transformation of the production process toward fuel-saving technologies (Solow 1978, 6).

The problem with these different definitions of substitution is that none of them are adequately represented by the model. Indeed, the first one is rather a substitution between resources than a substitution between capital and resources-but there is no variable in the model describing an alternative resource that would substitute for the exhaustible one. The second definition in turn relies on a substitution between produced goods, which cannot be represented explicitly in the model, because only an aggregate output is displayed. And similarly, the third one is rather a substitution between different kinds of capital, whereas only an aggregate capital variable appears in the model. The fundamental issue here is that, in all these definitions, the concept of substitution relies on underlying mechanisms that are not represented explicitly in the model. This creates an important discrepancy between its conceptual meaning and its mathematical representation.

Moreover, this makes substitution difficult to distinguish from technical progress. Indeed, the main illustration of the latter in the literature is that of "natural-resource-

\footnotetext{
14 Stiglitz (1976) concentrated on the implications of competitive markets and alternative institutional structures on the allocation of resources. Solow and Wan (1976) explored an elaborated version of the growth model with extraction costs of the resource, and Solow (1978) analysed data on the price and the availability of resources.
} 
saving technical progress" (Solow 1974a, 10), which seems very close to the third definition of substitution above. This shows that substitution and technical progress conceptually overlap and cannot be conceived in a strictly separated way. Conversely, at the mathematical level, they appear as distinct and independent properties. Once again, this reveals an inconsistency between the conceptual and the mathematical levels, or between the theory and the model.

My suggestion is that this issue comes from a "model-based" methodology, by which I mean that the model precedes the conceptual structure. The theory does not rely on a self-supporting understanding of the production process, and concepts are instead primarily forged as descriptions of the properties of the model. It is only in the second time, and in a succinct way, that Solow and Stiglitz try to describe them in more concrete terms. This in turn reveals that these concepts rely on mechanisms that are not explicitly represented in the model and that they tend to overlap ${ }^{15}$

In order to characterise what I mean more accurately, it is useful to rely on the history and philosophy of economic modelling. Following Morgan and Morrison (1999), it is conventional to recognise that models should not be conceived as mere descriptions of a target system in the real world. Instead, models involve many simplifications that make them autonomous objects, and, at the same time, allow manipulations of the model to perform various functions. Here for instance, models enable Solow and Stiglitz to identify the precise conditions under which the hypothetical economy they represent may support a constant level of consumption.

However Morgan and Morrison $(1999,11)$ also make clear that, "models typically represent either some aspect of the world, or some aspect of our theories about the world", and that this is necessary for models to be useful tools of investigation. Representation can be achieved through empirical methods, theoretical considerations, and also through more casual kind of observations of the world. It is this issue that is at stake in the way Solow and Stiglitz deal with substitution and technical progress. The conceptual elaboration of these notions remains vague and inconsistent with the mathematical properties associated with them ${ }^{16}$

Since the models appear to be the source of the concepts, and not the converse, it is important to understand the other reasons that determine the choice of the models of production used in neoclassical resource economics. The most interesting contribution in this respect is certainly one of Stiglitz (1979), who proposes a reflexive account of the foundations of neoclassical resource economics. It is all the more important because it results from his participation in a conference on Natural Resource Scarcity, organised in 1976 by Resources For the Future (RFF) $)^{17}$, and to which Georgescu-Roegen and Daly also participated. Hence, it offered the first occasion to confront their visions of the issue at stake.

The first set of justifications of the neoclassical approach relies on the empirical

\footnotetext{
${ }^{15}$ This characterisation of the methodology of Solow and Stiglitz is only intended to capture their approach to the issue of natural resources, and not their general methodological outlook. In the case of Solow, a more detailed account of his modelling practice has been given by Halsmayer (2014), which I discuss at various points below. To my knowledge, no such synthetic account exists for Stiglitz. However, himself provided important methodological insights in the case of neoclassical resource economics (1979), to be discussed later on.

${ }^{16}$ This interest for the issue of representation is the main difference with the account of Solow's modelling practice provided by Halsmayer (2014). Indeed, she insists mainly on the new theoretical and empirical functions that the neoclassical growth model enabled economists to perform. While I also acknowledge similar functions in the case of natural resources, I put more emphasis on the conceptual issues raised by the formalism of production functions.

${ }^{17} \mathrm{RFF}$ is an independent research organisation, established in 1952, that played a central role in promoting the economic analysis of environmental issues. See for instance Spash (1999) or Pearce (2002).
} 
relevance of the production functions it uses. On this point, Solow and Stiglitz generally refer to the estimates performed by Nordhaus and Tobin (1972) on constant elasticity of substitution (CES) production functions. These suggest elasticities greater than one and they interpret it as a demonstration of the important possibilities of substitution between capital and resources ${ }^{18}$ However, Stiglitz $(1979,44-45)$ acknowledges that, "the crucial question is what is to be taken as a constant" and he concedes that "resource pessimists" could oppose that "the particular parameterization implicit in the above calculation that the elasticity of substitution is constant is not correct: for example, they might argue that as resources become scarcer, the elasticity declines". To solve this problem, Stiglitz suggests to allow the elasticity to vary and test the assumption that it is constant. However, one might equally contest that, because the elasticity is constant according to past data, it will be constant under every condition of production, and in particular with a decreasing flow of resources. Hence, empirical estimates on past data cannot provide satisfactory justifications of production functions for long-term purposes. Instead, they must ultimately rely on theoretical justifications.

This leads to another set of justifications which imply mathematical concerns. It is illustrated by Solow's claim, already quoted above, to have an "interesting and substantial" problem whose solutions are not trivial (1974b, 34). A similar approach is endorsed by Stiglitz $(1979,44)$ when he insists on the distinction between "analytical methods" and "simulations". The former looks for the conditions that determine different answers to the problem. It is illustrated by conditions (3) and (5) in neoclassical resource economics. The latter instead gives numerical solutions for different values of the parameters. This is the methodology adopted in the report on The Limits to Growth (Meadows et al. 1972). Stiglitz defends the superiority of analytical methods because they allow to identify the exact frontier separating different behaviours of the model, while simulations only answer the problem for specific values of the parameters. However, analytical methods can only apply to relatively simple models. The analytical resolution, or the qualitative analysis, of differential systems is generally out of reach if the model is too complex. Good illustrations of this are Solow's repeated justifications that the Cobb-Douglas "[simplifies] the treatment of technical progress" $(1974 \mathrm{~b}, 34)$ or that, "a complete analysis of [the implications of unlimited technical progress] would be laborious" (40). Along this line, the choice of the Cobb-Douglas production function is implicitly linked to the simplistic representation of production it provides 19 .

Finally, another implicit motivation for choosing these kinds of production functions is the continuity with the tools used in traditional neoclassical growth theory, which had become very popular in the 1960s (Boianovsky and Hoover 2009). However, it denotes the absence of a reflection on the specificity of natural resources as a factor of production. The symmetric character of the Cobb-Douglas production function puts capital, labour, and resources on the same level. This also implies the transposition

${ }^{18} \mathrm{CES}$ production functions are of the form:

$$
Q=F(K, R, L)=\left[\alpha K^{\frac{\sigma-1}{\sigma}}+\beta R^{\frac{\sigma-1}{\sigma}}+\gamma L^{\frac{\sigma-1}{\sigma}}\right]^{\frac{\sigma}{\sigma-1}}
$$

The Cobb-Douglas is a special case of this family of functions, where the elasticity of substitution is unitary: $\sigma=1$. When $\sigma>1, R=0$ does not imply $Q=0$-that is to say that resources are not essential to production. In these conditions, it is possible to maintain a constant level of consumption across generations. Conversely, if $0<\sigma<1$, then resources are essential, but the productivity of resources is bounded and no constant level of consumption can be maintained indefinitely.

19 Halsmayer (2014) shows that the simplicity of Solow's growth model was acknowledged by himself and conceived as an alternative to complex models, such as Leontief's input-output tables or Keynesian macroeconometric models. In this context, it was justified, on the one hand, as a "prototype" on which more refined models should be built, and on the other hand, as a pedagogical tool in which elementary economic mechanisms could be explained transparently. 
from the traditional theory of the concepts of "substitution" or "technical progress", without adapting it to the specificity of natural resources. Hence, no consideration on the nature of the production process and on the interrelation of resources and other factors appears as the root of this choice.

Altogether, this shows that in the "model-based" methodology of Solow and Stiglitz, the preference for a specific representation is not grounded into a conceptual appreciation of the nature of the production process. Instead, it is determined by modelling practices and mathematical concerns. But Stiglitz $(1979,47)$ himself sets the problem at a conceptual level when he challenges "resource pessimists" to show that "as resources become scarcer we do not, or cannot, substitute less resource-intensive commodities for more resource-intensive commodities" and that, "the prospects are bleak for technical changes that would enable us better to use what resources we have". The next section examines the approach of Georgescu-Roegen, one of the so-called "resource pessimists", and his criticism of neoclassical resource economics.

\section{Georgescu-Roegen and Thermodynamic Limits to Production}

After dedicating his early academic career to the neoclassical theories of consumption and production, Nicholas Georgescu-Roegen became increasingly dissatisfied with this framework during the $1960 \mathrm{~s}^{20}$. His theoretical reorientation culminated into his book The Entropy Law and The Economic Process (1971). As this title suggests, GeorgescuRoegen advocates, among other things, to account for thermodynamic laws in economic theory ${ }^{21}$ and it is on this basis that he later criticised neoclassical resource economics.

\subsection{Thermodynamics and the Economic Process}

Thermodynamics can be broadly defined as the science of transformations of energy, and rests on two main principles ${ }^{22}$ The first principle states that the energy of an isolated system can change its form but its quantity is conserved. Georgescu-Roegen (1971, 5) illustrates this principle with the functioning of a "railway engine", where the chemical energy of coal is first transformed in thermal energy (heat) at a high temperature and then in mechanical energy (movement) plus thermal energy at a low temperature-but the total amount of energy is constant across the process.

The second principle of thermodynamics specifies what are the possible transformations between the different forms of energy. It stemed from the work on thermal engines of Sadi Carnot (1824), and was later reformulated in the formalism of energy by Rudolf Clausius. Carnot's main achievement was to prove that the efficiency of a thermal engine, such as the one used in the railway example above, has a theoretical maximum. This result means that a given amount of thermal energy cannot be fully transformed into mechanical energy ${ }^{23}$. whereas the opposite is possible. This is why

${ }^{20}$ The transition is well illustrated by his book Analytical Economics (1966), which contains his most important contributions to neoclassical theory, and an introduction to his new research program. However, historical accounts of the evolution of Georgescu-Roegen's thought underline that he has had a critical look on the foundations of neoclassical theory since the beginning of his career (Gowdy and Mesner 1998).

${ }^{21}$ This idea had had precursors before Georgescu-Roegen, such as Sergeï Podolinsky and Frederick Soddy. But they are less well known and he was not aware of them when he first suggested it. See Martinez-Alier (1987) for an account of these antecedents.

${ }^{22}$ Thermodynamics has two other principles which are not of interest for us here. See for instance Callen (1985 for an introduction to thermodynamics.

${ }^{23}$ More precisely, if the source of the heat flow $Q_{1}$ is at temperature $T_{1}$, if it is in an environment at temperature 
Georgescu-Roegen (1971, 129) distinguishes "available energy" to denote the share that can be transformed into mechanical work from "latent energy" that cannot. According to this distinction, Carnot's principle implies that "[available] energy always dissipates by itself (and without any loss) into latent energy", which is considered as a "qualitative degradation of energy". For instance, when mechanical work is transformed into heat at an atmospheric temperature, it is lost forever and cannot be recovered.

This statement can be reformulated using the concept of "entropy". According to Georgescu-Roegen (1971, 5), this achieves an, "analytical simplification and unification". However, he never formally defines entropy, which he considers to be unnecessarily technical, and he prefers the literal definition as, "an index of the relative amount of [latent] energy in an isolated structure 24 Then, the second principle of thermodynamics may be reformulated under the statement that the entropy of an isolated system increases toward a maximum, also known as the "entropy law".

These two laws are primarily concerned with the properties of energy. However, Georgescu-Roegen considers that they are also relevant for matter. Regarding the first law, this simply leads him to interpret it more broadly as the separate conservation of energy and matter $(1971,5)$. But he also suggests that matter is subject to a qualitative degradation equivalent to that of energy ${ }^{25}$ Hence, according to him, conservation and degradation are characteristics of both energy and matter.

These laws are central in Georgescu-Roegen's understanding of the economic process, which he describes as, "a continuous transformation of low entropy into high entropy, that is, into irrevocable waste" (1971, 281, italics in the original). As a consequence, the entropy law is considered as the physical principal underpinning the depletion of natural resources. For Georgescu-Roegen, this is true for energy resources such as coal and solar energy, but also for minerals such as copper. This leads him to underline the radical scarcity that governs these resources because, "first, the amount of low entropy within our environment (at least) decreases continuously and irrevocably, and second, a given amount of low entropy can be used by us only once" (1971, 278, italics in the original).

With this perspective, Georgescu-Roegen has been an important contributor to the renewed interest in natural resources issues in economics in the 1970s. However, The Entropy Law and the Economic Process did not reach a large audience and he had to wait for the debate on the limits to growth to find a more favourable context.

\subsection{Georgescu-Roegen's Criticism of Neoclassical Resource Economics}

When the debate started, Georgescu-Roegen offered his help to answer the criticisms addressed by economists to the Limits to Growth report (Levallois 2010). This led to his paper "Energy and Economic Myths" (1975) and it was an opportunity to promote his own approach.

In this paper, after recalling his thermodynamic approach of the economic process, Georgescu-Roegen suggests to distinguish between "available" and "accessible" energy.

$T_{0}<T_{1}$, and if $W$ is the amount of work produced, then the efficiency of the engine $\eta=\frac{W}{Q_{1}}$ is bounded by Carnot's coefficient:

$$
\eta_{m}=\frac{T_{1}-T_{0}}{T_{1}}<1
$$

${ }^{24}$ See Callen 1985 ) for a more complete introduction to this concept.

${ }^{25}$ Georgescu-Roegen ended up thinking that the dissipation of matter had been ignored by thermodynamics and that it deserved the status of a fourth law. This has become one of his most controversial claims and it has raised many comments in ecological economics. See for instance Cleveland and Ruth (1997), and Ayres (1999). 
He notes that extracting available energy from its deposit, for example in oil wells, and making it properly useful, implies to spend some energy to extract, transport, and refine the resource. If the energy spent in this process is less than the energy obtained, then the resource is said to be accessible. Otherwise, the deposit is not energetically profitable. In this context, he calls "efficiency" the ratio of the energy extracted over the energy spent, and he writes:

To be sure, actual efficiency depends at any one time on the state of the arts. But, as we know from Carnot, in each particular situation there is a theoretical limit independent of the state of the arts, which can never be attained in actuality. In effect, we generally remain far below it. (Georgescu-Roegen 1975, 355)

This statement is the first occurrence of the idea of thermodynamic limits in Georgescu-Roegen's work ${ }^{26}$ It clearly refers to Carnot's maximum efficiency of thermal engines, which is presented as a typical kind of limit that thermodynamics may impose on production processes, and in particular on energy extraction. But Georgescu-Roegen goes further and suggests that Carnot's coefficient implies thermodynamic limits to technical progress in general:

Even if technology continues to progress, it will not necessarily exceed any limit; an increasing sequence may have an upper limit. In the case of technology this limit is set by the theoretical coefficient of efficiency. (Georgescu-Roegen 1975, 362)

This proposition suggests that the production of any economic good or service requires a theoretical minimum consumption of energy, and it is presented as a general counter-argument to the technological optimism of the economists that criticise the Limits to Growth report. Georgescu-Roegen notices in particular that, "in Solow's hands, substitution becomes the key factor that supports technological progress even as resources become increasingly scarce" $(1975,362)$. But the analytical framework of neoclassical resource economics and the assumption of "unbounded resource productivity" are not discussed in detail.

The relationship became more direct later on, when Georgescu-Roegen (1979) formulated a criticism of the work of Solow and Stiglitz, and especially of the analytical representation of production on which it rested 27 . This contribution resulted from his participation in the RFF conference on Natural Resource Scarcity held in 1976. On this occasion, he was asked to comment on the papers presented by Stiglitz and Daly in the session devoted to the role of natural resources in production. He made it clear that he shared most of the vision of the latter, and that he was instead, "entirely out of sympathy with the manner in which J. E. Stiglitz dealt with his topic" (95). Focusing on the assumption of unbounded resource productivity incorporated in the Cobb-Douglas production function, he put forward different arguments against it, which I critically examine here.

First, Georgescu-Roegen $(1979,97)$ argues that "the increase of capital implies an additional depletion of resources" and suggests that if capital increases toward infinity, then, "[resources] will rapidly be exhausted by the production of capital". However, Solow's and Stiglitz's works are consistent with the premise that the production of

\footnotetext{
${ }^{26}$ In particular, it does not appear in The Entropy Law and the Economic Process.

${ }^{27}$ Georgescu-Roegen's criticism concerns other aspects of neoclassical resource economics as well. For instance, he denies that the appropriate intergenerational distribution may be achieved by market processes alone and questions the relevance of empirical estimates of production functions. However, these topics were not tackled in the 1997 debate. Therefore, they are less useful to understand the opposition between ecological economists and neoclassical resource economists.
} 
capital depletes resources. In their models, the increment of capital at every moment is taken from the aggregate product-itself produced thanks to resources. This does not prevent capital from increasing to infinity in Solow's model, precisely because the productivity of resources increases faster and enables the flow of resources to decrease toward zero. Hence, this model is consistent from a mathematical point of view, and Georgescu-Roegen's first argument is not sufficient.

This leads to the second argument, according to which, "any material process consists in the transformation of some materials into others (the flow elements) by some agents (the fund elements)". The distinction between flows and funds in this statement suggests a difference in nature between the various factors of production ${ }^{28}$. While natural resources are transformed in the process of production, capital and labour are agents of this transformation. In this framework, the notion of substitution appears misleading in the sense that capital cannot play the same role as resources in production. According to Georgescu-Roegen, "a change in capital or labor can only diminish the amount of waste in the production of a commodity" $(1979,97)$. However, this truly represents a limit only for material requirements, and if it is assumed that goods remain qualitatively identical.

In order to generalise his argument beyond this restricted case, Georgescu-Roegen rests once again on the idea of a general limit to the productivity of resources:

In some cases it may also be that the same service can be provided by a design that requires less matter or energy. But even in this direction there exists a limit, unless we believe that the ultimate fate of the economic process is an earthly Garden of Eden. (Georgescu-Roegen 1979, 97-98, I emphasise)

This idea appears to be the true logical foundation of Georgescu-Roegen's criticism. Without it, the assertion that the increase of capital to infinity implies the exhaustion of resources is not justified. However, compared to the initial statement in 1975, which focused on energy, Georgescu-Roegen suggested that this kind of limit applies to both energy and matter. Once again, the underlying idea is that the laws of thermodynamics set constraints on the use of natural resource 29 .

\subsection{Interdisciplinary Consistency}

From the various contributions of Georgescu-Roegen examined above, there emerges an assumption of thermodynamic limits to the productivity of resources. It appears as the logical foundation of his criticism of the assumption of unbounded resource productivity and his most consistent theoretical answer to the challenge addressed by Stiglitz

${ }^{28}$ This distinction is the cornerstone of Georgescu-Roegen's theory of production, known as the flow-fund model (1971, chap. IX). This approach has been further developed along two distinct lines of research: the organisation of a single production process-see Vittucci Marzetti (2013) for a survey-and the interaction between multiple production processes-see Kurz and Salvadori (2003) for a comparison with Sraffa's model. However, these developments are not concerned with the role of natural resources.

Other contributions employed the distinction between flows and funds to discuss the notion of substitution Anderson 1987. Mayumi, Giampietro, and Gowdy 1998 van den Bergh 1999). Yet, the analytical framework of the flow-fund model is not mobilised more extensively, either by Georgescu-Roegen or other ecological economists, to formulate their criticism of neoclassical resource economics. This is the reason why the flowfund model deserves to be treated separately.

${ }^{29}$ Georgescu-Roegen's later contributions do not give much more details on these arguments. Here and there, some allusions to the work of Solow and Stiglitz can be found (Georgescu-Roegen 1981, 1986, 1988), but the assumption of thermodynamic limits is not mentioned any more. Moreover, I could not find any interesting insights on these issues in the archives of Georgescu-Roegen and Solow, available at the Rubenstein Library of Duke University. No direct correspondence between them is available, and no other material brings new and important elements to light, as far as the present paper is concerned. 
to "resource pessimists" $(1979,47)$. In order to better understand the nature of this opposition, it is worth examining the methodological foundations underpinning this assumption.

Missemer $(2013,19)$ has already insisted on the idea that the choice of scientific referents exterior to economics, such as thermodynamics or biology, is one pillar of Georgescu-Roegen's methodology. He underlines that the goal is not to bring formal analogies from one discipline to another, but to capture essential properties of the objects under study thanks to the existing body of knowledge. If we refer to the taxonomy of disciplinary exchanges established by Klein (2010), this corresponds to the idea of "theoretical interdisciplinarity". It implies strong interactions between disciplines in order to build new conceptual foundation 30 .

An important additional aspect of the interaction between thermodynamics and economics in Georgescu-Roegen's approach is that it goes one way: thermodynamics is used as a source of conceptual inspiration in order to reform the foundations of economics. The implicit idea behind this kind of interdisciplinarity is that thermodynamics is a mature and reliable science, whereas economics is an unsatisfying intellectual edifice. The former is well illustrated by Georgescu-Roegen's reference to Sir Arthur Eddington-a physicist and philosopher of science-who considers that the entropy law occupies "the supreme position among the laws of nature", and that if a theory is not consistent with it, "there is nothing for it but to collapse in deepest humiliation" (Eddington 1928. quoted in Georgescu-Roegen [1982] 2011, 197). This is why I suggest to speak of "interdisciplinary consistency" to describe Georgescu-Roegen's methodology. It involves an asymmetrical relationship in which economics is required to become consistent with the laws of thermodynamics.

Of course these characteristics of Georgescu-Roegen's methodology make sense only if we also presuppose another implicit condition, which is more of an ontological nature: both disciplines share, at least partially, an interest in the same objects. In the present case, this requirement is supported by the idea that economics should deal with the physical facet of economic activities, and more precisely with the role of energy and matter. If this idea is accepted, then, since thermodynamics is one of the branches of physics concerned with the transformations of energy and matter, economics should account for its relevant theoretical consequences. Hence, this perspective may be characterised as a "hierarchical ontology", where the economy is embedded in the physical world (Spash 2012, 43).

However, this does not mean that Georgescu-Roegen promotes a physically reductionist approach to economics. Conversely, he is explicitly opposed to such a perspective. This is clear if we consider the way he analyses the relationship between entropy and economic value. He asserts that "low entropy [...] is a necessary condition for a thing to have value", but he adds that, "this condition [... is not also sufficient" $(1971,282)$ Moreover, according to him, the first part of this claim is a consequence of the origins of thermodynamics itself. The distinction between "latent" and "available" energy is economically laden because it rests on the fact that, "we can use the latter but not the

${ }^{30}$ This taxonomy distinguishes "theoretical interdisciplinarity" as above from "methodological interdisciplinarity", involving only the transfer of methods or tools from one discipline to another. Moreover, theoretical interdisciplinarity is explicitly endorsed by recent contributions to the philosophy of ecological economics (Baumgärtner et al. 2008, Spash 2012), where it appears tightly linked with the influence of Georgescu-Roegen.

${ }^{31}$ Georgescu-Roegen illustrated his point of view with, "the case of poisonous mushrooms which, although they contain low entropy, have no economic value" 1971,282$)$. This led him to criticise earlier attempts to reduce economic value to low entropy, such as those of the German physicist Georg Helm or the Polish sociologist Leon Winiarski. 
former" (277) ${ }^{32}$ Hence, the intricate relationship between thermodynamic concepts and economic value is an important aspect of Georgescu-Roegen's approach, but it leaves a certain degree of flexibility as to how exactly they articulate together.

Therefore, we may summarise the features of Georgescu-Roegen's methodology as follows: a hierarchical but non-reductionist ontology; reliability of the scientific referent; and conceptual integration. This approach appears antithetical with respect to the model-based methodology of Solow and Stiglitz. It insists on the necessity to understand first the physical features that characterise the production process in order to build conceptual and analytical tools that are consistent with this view. Hence, behind the theoretical opposition between the assumptions of unbounded resource productivity and thermodynamic limits to production, there is an important methodological opposition.

Moreover, these methodological insights are useful to point out the issues that Georgescu-Roegen's approach faces. Starting with ontological aspects, we may notice that Georgescu-Roegen's focus on the physical facet of the economic process, even though it is not unfamiliar in the history of economic thought, is considerably original and not easily acceptable for most economists. Classical economists, such as Smith, Ricardo, and Babbage were interested in the material aspects related to agricultural and industrial activities. But neoclassical economics focused more exclusively on allocative issues, and its representation of production did not leave room for more material aspects (Christensen 1989). The figure of Stanley Jevons is particularly interesting. While his book The Coal Question warned about the consequences of coal depletion on the economic supremacy of Great Britain, natural resources were absent in his contribution to the foundations of neoclassical theory. Moreover, even when some neoclassical economists were interested in resources, their perspective has been "reductionist" (Missemer 2017a) ${ }^{33}$ They analysed them only as a specific isolated market on which to apply neoclassical tools, and not as a fundamental factor of production with potentially important consequences on growth. In this context, Georgescu-Roegen's insistence on the role of energy and matter in the economic process appears as a radical divergence with the implicit ontology that dominated economics at the time ${ }^{34}$. However, this does not characterise an internal issue inherent to his approach, but rather a strong disagreement with the rest of the economic community.

Conversely, the way Georgescu-Roegen interpreted the laws of thermodynamics revealed shortcomings that are proper to his perspective. First, in his original mention of the idea of thermodynamic limits, he considered the process of extracting energy resources from their deposit and he related it to Carnot's maximum efficiency of thermal engines. But this process is very different from that of a thermal engine, where the mechanical energy produced is a direct transformation of thermal energy. In energy production, the resource extracted-oil for instance-is not a transformation of the energy spent, which is only used to build and run the infrastructures that will extract the former from a pre-existing deposit. Therefore, Carnot's principle cannot be straightforwardly applied in this context, and the proposition would at least need some more

\footnotetext{
${ }^{32}$ On another occasion, Georgescu-Roegen put it even more clearly: "The point is that it was the economic distinction between things having an economic value and waste which prompted the thermodynamic distinction, not conversely." (Georgescu-Roegen 1976 54).

${ }^{33}$ The notion is used here in a slightly different way than before. Indeed, what is at stake is rather a theoretical reductionism, related to which questions are considered relevant, and not an ontological reductionism.

${ }^{34}$ Georgescu-Roegen's approach emerged in a rather favourable context, marked by the rise of environmental preoccupations, oil shocks, and the debate on limits to growth. But as it appears from Solow's work for instance, this was not interpreted as the necessity for economists to revise the conceptual foundations of their theories, but rather to consider these issues from the point of view of their pre-established theories.
} 
arguments to be convincing.

Second, Georgescu-Roegen's various presentations on the idea of thermodynamic limits revealed an ambiguity on which entities and which laws should be considered. The first mention in 1975 focused on energy and attributed the limits to Carnot's principlethat is to the second law of thermodynamics. But in 1979, both matter and energy requirements for production were assumed to have a lower limit, and there was no explicit reference to a particular law of thermodynamics. This shows that, as reliable a scientific referent as thermodynamics may be, its consequences for economics are not straightforward. An accurate analysis of what exactly is relevant for this purpose is needed and Georgescu-Roegen is not sufficiently clear on this point.

Finally, Georgescu-Roegen's methodology requires a conceptual integration between thermodynamics and economics. His claim that low entropy is a necessary, but not sufficient, condition for a thing to have economic value is the first step in this direction. However, it does not tell how much economic value one can produce thanks to a given amount of low entropy. But precisely, the question of how tight this relation is appears at the heart of the controversy with neoclassical resource economists. This was particularly obvious in 1975, when Carnot's maximum efficiency was assumed to set a general limit to "technological progress". But it is also perceptible in the statement of 1979, where the limit applies to the "services" that can be provided by material and energy flows. In both cases, the idea of a limit involves a mix of thermodynamic and economic concepts, whose relationships have not been comprehensively investigated.

\section{The Direct Confrontation between Ecological and Neoclassical Resource Economics}

In 1997, an issue of the journal Ecological Economics was dedicated to GeorgescuRoegen, who had died three years before. On this occasion, Herman Daly revived his criticism of neoclassical resource economics with a paper called "Georgescu-Roegen versus Solow/Stiglitz" (1997a). Daly is a former student of Georgescu-Roegen and he has been much influenced by his thermodynamic approach of the economic proces ${ }^{35}$ From a similar framework, he developed a more policy-oriented perspective, and was particularly critical of what he perceived as a "growthmania" among economists. He suggested to reorient economic policies toward a "steady-state economy" defined by "constant stocks of physical wealth (artifacts) and a constant population" (Daly 1974. 15). In this context, he had already made general assertions regarding the idea that, "the laws of thermodynamics provide a theoretical limit to the improvement of maintenance efficiency". Like Georgescu-Roegen, it was at the 1976 RFF conference on Natural Resources Scarcity that he aimed his criticism more specifically at the work on natural resources of neoclassical growth economists (Daly 1979) However, at that time, the controversy went only in one direction: Georgescu-Roegen and Daly criticised Solow and Stiglitz, without any real answer. This is an important difference with the 1997 debate examined in this section.

On this occasion, Daly focused the discussion on the assumption of "thermodynamic limits" to production as a counterargument to "unbounded resource productivity". In

\footnotetext{
${ }^{35}$ For instance, he stated that the economic process, "begins with the extraction (depletion) of low entropy resources at the input end, and terminates with an equal quantity of high entropy waste (pollution) at the output end" (Daly 1974 15).

${ }^{36}$ Georgescu-Roegen's contribution remains the most detailed criticism, as he was specifically asked to comment on the paper of Stiglitz. Daly instead mostly presented his own vision.
} 
their replies, Solow and Stiglitz defended their assumption (Solow 1997, Stiglitz 1997). Among other ecological and neoclassical resource economists, some clearly sided with Daly's and Georgescu-Roegen's arguments (Clark; Common; Opschoor, Peet; Tisdell), some proposed a more nuanced opinion (Ayres||Pearce: Castle), and others denounced the polemical tone of the debate (Turner: Perrings). This remains one of the few direct confrontations between these two approaches and shows the importance of the issues at stake. As a result, it appears as a landmark in the related literature, which often refers to it. But a comprehensive account of the issues raised by the controversy is missing. This is the reason why it appeared necessary to examine the original works on which the debate is built in order to apprehend what remains the same and what has changed between the two periods.

Before proceeding with this investigation, it is important to note that the debate of 1997 happened in a new intellectual context that crystallised around the concept of "sustainability". One of the reasons for this was the report of the World Commission on Environment and Development entitled Our Common Future, where "sustainable development" was defined as, "[meeting] the needs of the present without compromising the ability of future generations to meet their own needs" (Brundtland 1987, 6) ${ }^{37}$. In economics, it became the new battleground of neoclassical resource economists and ecological economists, which provided two opposing interpretations of sustainability. On the one hand, "weak sustainability" argued for the possibility of substituting human-made capital to natural capital as it is depleted. Solow (1993) was an important and early contributor of this approach, which appears as an extension of the concept of substitution as developed in growth models with exhaustible resources ${ }^{38}$ On the other hand, ecological economists, especially Daly (1990), supported the idea of "strong sustainability", according to which there are limits to substitution of human-made capital to natural capital, and specific natural life-supporting functions must be preserved ${ }^{39}$. The controversy at stake here offers the opportunity of exploring some of the foundations of the opposition between weak and strong sustainability ${ }^{40}$.

\subsection{Time Horizon of Models and the Laws of Thermodynamics}

The first question raised by the debate concerned the relevant interpretation of the time horizon of models. It was triggered by Stiglitz's assertion that their models are only meaningful "for the intermediate run"-that is "for the next 50 - 60 years". They are written "as if they extend out to infinity, but no one takes these limits seriously" (1997, 269). This argument is discussed by a number of comments in the debate, which strongly deny its relevance (Daly, Clark, Opschoor, Tisdell). They consider that this time horizon is not suitable for ecological purposes, such as resource depletion or climate change, which have both short and long-term consequences. They also think that the argument is an ad hoc interpretation put forward to avoid criticisms and that it had never been formulated before.

Even though no one noticed it in the debate, this last opinion is vindicated by the

\footnotetext{
${ }^{37}$ This definition has been the most influential, but it was not the first one. For instance, the International Union for Conservation of Nature had already given one its report World Conservation Strategy (1980).

${ }^{38}$ This use of the concept of substitution is an extension because it concerns natural capital as a whole, which also includes climate stability and ecosystems, for instance.

${ }^{39}$ In this context, Victor (1991) had already highlighted the crucial role played by the different approaches to substitution and technical progress in production. However, he did not identify the idea of thermodynamic limits as a central argument.

${ }^{40}$ The debate between weak and strong sustainability had been particularly intense during the 1990s and 2000s (Pezzey and Toman 2005 Neumayer 2013), but it has become less central in recent years.
} 
fact that Solow and Stiglitz have supported opposite positions on this topic. Indeed, Stiglitz notices that, "an exponential increase in the population presents almost unimaginable problems of congestion on our limited planet" (1997, 269), and presents this as a justification for his medium-run interpretation of the time horizon of models. On the other hand, Solow had asserted that, "on a time-scale appropriate to finite resources [...] exponential growth of population is an inappropriate idealization" (1974b, 36), which implicitly suggests a long-run interpretation. Hence, similar to what has been identified in the case of "substitution" and "technical progress" in section 2 , this shows that there is no proper conceptualisation of the role of time in these models. Time is first of all a mathematical variable, whose meaning outside of the models is not stabilised. The multiple interpretations that arise, and vary across time, happen to be in contradiction with each other and at odds with the basic features of the models.

Reciprocally, the interpretation of the entropy law is questioned by neoclassical resource economists. For instance, Solow suggests that it is, "of no immediate practical importance for modelling what is, after all, a brief instant of time in a small corner of the universe" (1997, 268). This argument involves both temporal and spatial scales. It shows that Solow interprets the entropy law only as a long-term and global driving force of the universe. Accordingly, it would bear no significance for economic activities because they unfold on a shorter time-scale and in smaller systems. This point of view is criticised by Daly, who underlines the practical consequences of the entropy law-for instance "that you can't burn the same lump of coal twice", or "that there are limits to the efficiency of conversion of energy" (1997b, 273). Hence, the opposition rests here on the ambiguous relationship between two interpretations of the entropy law that we may label respectively as "cosmological" and "practical".

If we look at earlier contributions, these different interpretations are not new, but they were distributed slightly differently among the two opposing approaches. For instance, Solow (1974a, 2) had supported a more practical interpretation before, suggesting that the laws of thermodynamics constrain possibilities of recycling. Stiglitz (1979. 37 instead already focused on the cosmological one. Georgescu-Roegen in turn made statements that supported either the cosmological view $(1971,19,231)$ or practical economic consequences $1971,6,278)$. Moreover, in the history of thermodynamics, the practical interpretation seems to be the original one if we consider the fact that the entropy law grew out of the study of thermal engines by Carnot. However, it was later interpreted by Clausius as a general law of evolution of the universe.

In an interdisciplinary perspective, this duality becomes confusing, as different authors privilege one interpretation or the other. However, these two interpretations are not contradictory, and we may instead consider that both are constitutive of the entropy law 41 Therefore, invoking the cosmological meaning of the entropy law cannot justify putting aside more practical consequences for economic activities.

These immediate consequences are at stake in the confrontation between the assumptions of "unbounded resource productivity" and "thermodynamic limits", which is the central subject of the debate. Relying on Georgescu-Roegen's 1979 criticism, Daly presents the issue as follows:

In the Solow-Stiglitz variant [of production function], to make a cake we need not only the cook and his kitchen, but also some non-zero amount of flour, sugar, eggs, etc. This seems a great step forward until we realize that we could make our cake a thousand

\footnotetext{
${ }^{41}$ More generally, the implications of physical laws both at the practical and at the cosmological levels are common in physics. The laws of mechanics, for instance, apply to the movements of planets as well as playing basketball.
} 
times bigger with no extra ingredients, if we simply would stir faster and use bigger bowls and ovens. The conjuring trick is to give the appearance of respecting the first law of thermodynamics (material balance) without really doing so. (Daly 1997a, 263, I emphasize)

Here, Daly's interpretation of Georgescu-Roegen has two important implications. First, it focuses on the first law of thermodynamics rather than the entropy law. Second, it interprets this law as the conservation of mass, and therefore focuses the debate on the role of matter rather than energy. According to this perspective, thermodynamic limits rest on the fact that the mass of matter that goes out of the production process, under the form of commodities or waste, is equal to the input of matter at the entrance of the production process. Hence, the mass of input matter is necessarily greater or equal to the mass of output commodities, and this defines the minimum requirement of matter.

This echoes another issue related to the interpretation of the laws of thermodynamics, on which Georgescu-Roegen and Daly had disagreed before. Georgescu-Roegen (1977) thought that Daly's promotion of a "steady state" as an alternative to growth was inconsistent with the laws of thermodynamics. His argument rested on the idea that only a finite stock of matter is available on Earth, and that it is subject to qualitative degradation through dissipation-just as energy is qualitatively degraded because of the entropy law. To my knowledge, Daly never formally opposed Georgescu-Roegen's argument. However, the dissipation of matter is not logically compatible with the steadystate objective and the idea of minimum requirement of matter. Hence, to be consistent, this last assumption requires implicitly that Daly should not agree with GeorgescuRoegen on the dissipation of matter.

Moreover, if we consider the historical account of the idea of thermodynamic limits in Georgescu-Roegen's work as presented in section 3, this interpretation appears as a relative reversal. Indeed, the original statements in 1975 clearly referred to Carnot's coefficient of maximum efficiency-that is to the question of energy and the entropy law. Even in the 1979 paper-which is the main source of Daly-Georgescu-Roegen mentioned both matter and energy without precision on the laws involved. This outcome in turn is partially explained by the fact that Georgescu-Roegen's own interpretation of the practical consequences of the laws of thermodynamics was not sufficiently clear. As a result, most subsequent work that investigated the idea of thermodynamic limits to production have followed Daly's interpretation van den Bergh 1999. Baumgärtner 2004). The only author that adopted a more general interpretation and tried to include in a formal model both energy and matter conservation, as well as the entropy law, seems to be Krysiak $2006{ }^{42}$

\subsection{Thermodynamics, Economics, and their Conceptual Integration}

However, this last perspective still misses another important aspect of the controversy: the conceptual integration between thermodynamics and economics. In this respect, the debate of 1997 raised the question of the relevant units for measuring production. Daly asserted that, "even production functions that yield services are producing a physical output - the use of something or somebody for some period of time" (1997a, 264), to which Stiglitz replied that, "output is measured not in physical units, but in the value of

${ }^{42}$ It is useful to make clear that this claim is restricted to the introduction of the laws of thermodynamics in formal models. At the conceptual level instead, the entropy law remains an important reference in ecological economics. 
the services associated with it" $(1997,269) \sqrt{43}$. Moreover, even some ecological economists are sceptical about Daly's assertion. Ayres, for instance, admits that, "human welfare is attributable in the final analysis to non-material services" that have "a material base", but he denies that, "there is some finite upper limit to the service output of a given material [...] given the possibility of dematerialization, re-use, renovation, recovery and recycling" 1997,286$){ }^{44}$

The attempts to incorporate thermodynamic laws in formal models (Baumgärtner 2004; Krysiak 2006) do not take this issue into consideration. They simply consider that produced commodities are measured according to their mass and energy content. Hence, conservation laws lead to inequalities of the form $Q \leq R$, which are interpreted as incompatible with the assumption of unbounded resource productivity. This is not satisfying from an economic point of view as long as mass and energy units cannot be connected to economic concepts, such as services or values. Similarly, the assertion of neoclassical resource economists that production may be directly measured in value obliterates the physical side of the issue.

This shows that the conceptual integration of thermodynamics and economics is not fully achieved in this controversy. Even though they do not completely solve this issue, contributions of ecological economists that care for economic concepts-such as Ayres (1997)-help to locate where the problem stands. They show that the notion of production itself has to be refined to be able to assess its dependence on natural resources. More precisely, the relationship between material and energy resources, the goods they enable to produce, and the non-material services these provide, appears at the heart of the issue. In addition, the debate highlights that, since the idea of limits presupposes a quantitative relation, the units according to which concepts are measured matter. While thermodynamics relies on energy or mass units, the production of goods and services have usually been associated with a value measure in economics, and it is necessary to articulate both together.

On the other side of the controversy, Solow and Stiglitz are also confronted with the same issues raised by their "model-based" methodology as they were in the 1970s. This is the case in particular for "substitution" and "technical progress". For instance, Solow asserts that, "the substitution between renewable and nonrenewable resources is the essence of the matter" (1997, 267), and this question is perceived as an important aspect of the debate by some ecological economists too (Clark 1997; Ayres 2007). However, this interpretation of substitution is still not consistent with Solow's and Stiglitz's original models-no such renewable resources are represented and substitute for the exhaustible ones.

Stiglitz in turn suggests that the substitution between capital and resources is about, "more precise machines (made out of resources that are relatively abundant) [that] can reduce wastage of resources that are relatively scarce". This shows that there is no agreement on what is the important feature behind the idea of substitution. This interpretation is hardly consistent with the models, whose aggregate variables do not enable one to represent a change in the nature of capital goods. Moreover, substitution still overlaps with technical progress, which is defined by Stiglitz as allowing to "reduce the amounts of physical capital and resources required to produce the unit of output"

\footnotetext{
${ }^{43}$ This question is not mentioned in the early works of Solow and Stiglitz on natural resources. I could only find an allusion in one of Solow's original paper on growth theory, where he states that, "Q represents output and K and L represent capital and labor inputs in "physical' units" (1957, 312). This shows at least that the appropriate units for production are uncertain.

${ }^{44}$ Following the same line, van den Bergh asserts that, "both the service output of materials processing and the value of this service output do not seem to be bounded by an identifiable absolute limit" (1999, 554).
} 
(1997, 269). Hence, an overall confusion remains about the meaning of substitution and technical progress, and their relationships with the corresponding properties in the models.

This is underlying Daly's criticism of the lack of, "distinction between substitution among factors within a given set of technologies (existing state of the art), and substitution among factors made possible by a new technology (improved state of the art)" (1997a 264). This distinction aims at a more direct argument against unbounded resource productivity. It underlines that if the production function is supposed to represent actual possibilities of production, then the productivity is bounded because the set of technologies available at every moment is necessarily limited. However, for Daly, Georgescu-Roegen's claim about thermodynamic limits remains a relevant constraint for future technologies.

Solow and Stiglitz have not considered this issue in their replies. Nevertheless, we can analyse what this distinction would change in the conceptual issues they face. From this point of view, since technical progress depends on time in their models, it fits best with the idea of an improved state of art. Conversely, substitution between capital and resources is independent of time in production functions, and therefore would correspond to the idea of an existing state of art. Hence, this could improve the conceptual distinction between substitution and technical progress. But this may compel neoclassical resource economists to accept Daly's proposition that the former cannot provide the unbounded productivity of resources they assume. Analytically, it means that at every given moment the productivity of resources should be bounded from above, and therefore the Cobb-Douglas structure is not satisfying. This would particularly affect the relevance of Solow's model. But a time-dependent factor of technical progress would be admissible, and Stiglitz's results could potentially be maintained with another production function because they mainly depend on this factor. However, this would not solve the whole debate. The issue of whether technical progress can achieve unbounded resource productivity, or is constrained by thermodynamic limits, would remain.

The issues raised by this debate have later been well captured by Mayumi, Giampietro, and Gowdy (1998) and van den Bergh (1999). The latter in particular shows that the use of aggregate variables in neoclassical models prevents from examining the possibilities of substitution more precisely. He suggests instead to distinguish direct substitution between production factors "having the same function", from indirect substitution between "multiple categories of production factors, which fulfill different, and often complementary, functions" (549). This distinction is used to provide a classification of the different substitutions that may affect the use of energy, materials, capital, and labour in the economic process. It does not tell which are the more relevant a priori, but instead is presented as a conceptual framework for further empirical investigations of the issue.

Moreover, van den Bergh adequately acknowledges that focusing only on the physical dimension of the economic process does not solve the issue more than the conventional neoclassical approach. He explains instead that, "the interaction between physical and value dimensions, which is at the heart of the matter, is not really touched upon in either approach" (552). While this diagnostic is interesting, the answer he proposes seems less fruitful. Indeed, van den Bergh uses an aggregate model of production very similar to those of neoclassical economists, whose main innovation consists of introducing a "transformation function" between physical and value measures. Hence, the initial debate between unbounded resource productivity and thermodynamic limits is only reformulated under the question of whether this function can produce a constant or growing value with a decreasing physical flow going through the production pro- 
cess. With this question, most of the issues regarding the integration of economic and thermodynamic concepts remain.

\section{Conclusion}

The analysis above shows that between its two most active periods, in the 1970s and at the end of 1990s, the controversy between ecological and neoclassical resource economics rested on the same theoretical and methodological oppositions-even though the more direct confrontation in the second phase unveiled new features. The central theoretical problem is the conflict between the assumptions of "unbounded resource productivity" and "thermodynamic limits", which are associated with two different methodologies respectively characterised as "model-based" and "interdisciplinary consistency". Overall, the conclusion is that neither side has been able to provide a definitive proof of the validity of its own claim because both face important conceptual issues.

On the one hand, in Solow's and Stiglitz's works, the assumption of unbounded resource productivity rests on the concepts of "substitution" and "technical progress". But these concepts are first associated with mathematical properties of production functions, because, in the model-based methodology, the model precedes the conceptual structure of the theory. It is only at a second stage, and in a succinct way, that Solow and Stiglitz relate substitution and technical progress to various mechanisms implying changes in the type of resource, capital, or produced goods. However, these mechanisms are not explicitly represented in their models, and according to these definitions, substitution and technical progress tend to overlap. This reveals the difficulty for concepts that primarily arise from a model of making sense outside of the model. In this respect, the debate of 1997 brought forward the distinction between the actual and improved state of art, suggested by Daly. This may clarify some aspects of the question-at the price of forsaking the Cobb-Douglas function. But overall, the confusion surrounding those concepts lasted over time, leaving a sense of uncertainty about the relevance of the assumption of unbounded resource productivity.

On the other hand, Georgescu-Roegen's methodology of "interdisciplinary consistency" is clearly endorsed by Daly and most other ecological economists. They insist on necessity to account for thermodynamic constraints on the economic process, but they do not solve the conceptual issues that this involves. First, this approach presupposes a clear interpretation of thermodynamic limits and of which laws are relevant for this purpose. Georgescu-Roegen hinted at various possible interpretations, involving either matter or energy, and either the first or the second law of thermodynamics. Daly's interpretation instead focuses on the conservation of mass, which appears as a relative reversal regarding Georgescu-Roegen's original reference to Carnot's principle-that is to energy and the second law. A more cautionary approach would be to consider the constraints related to both energy and matter, and to examine their respective relevance. But this assessment raises the issue of the conceptual integration between economic and thermodynamic concepts. In this respect, Georgescu-Roegen suggested that low entropy is a necessary condition for value, but the idea of thermodynamics limits suggests a quantitative relationship between the two that remains mostly unexplored. The debate of 1997 underlines that the notion of production itself needs to be questioned in order to improve this integration. In particular, the relationships between natural resources, produced goods, and the non-material services they provide seem to be at the heart of the issue.

Throughout the controversy, the question of how models may appropriately represent 
theoretical concepts appears as a central preoccupation. In particular, the controversy raises many questions about production functions-some of which go beyond the case of exhaustible resources and reveal more general issues regarding the neoclassical theory of production. Paradoxically, ecological economists seem unable to escape from this analytical representation of production and do not provide a clear alternative to this model. By the end of his paper, Daly suggests that, "Georgescu's fund-flow model of the production process is superior to the neoclassical production function" $(1997 \mathrm{a}, 265)$, and Georgescu-Roegen himself had mentioned it in his criticism of neoclassical resource economics. But the relevance of the flow-fund model is never examined in more details, nor used to formalise the issues at stake.

On the other side of the controversy, Stiglitz apparently did not contribute any more to natural resources issues, but Solow came back at least twice on the subject. In the first case (2009b), he briefly mentioned it as one of the four challenges that should be better taken into account in future growth theory, along with services, international trade, and inequalities. However, the second contribution shows that his outlook on the issue had significantly changed by that time. Focusing on energy, he asserted that the concept of "backstop technology" introduced by Nordhaus in the 1970s is, "a more sensible, more realistic, way to think about the very long run than the kind of maximum-feasibleconstant-consumption-path exercise", which he had considered in 1974. This means that the central issue should not be the distribution of an exhaustible resource over an infinite time horizon any more, but the transition to a technology based on a renewable resource, such as the "energy from direct solar, wind, biofuels" (2009a, 5). This appears as if he admitted that in the long-run the increased productivity of an exhaustible resource cannot be sufficient to offset its depletion, and that his model was not relevant to account for a substitution between different resources. Even though Solow does not refer to the controversy with Georgescu-Roegen and Daly, this sounds like a concession to them.

\section{Acknowledgements}

I would like to thank Robert Dimand, Marco Franco, Christophe Goupil, Jérôme Lallement, Antoine Missemer, Antonin Pottier, and Fatma Rostom for their helpful comments and suggestions on earlier versions of this paper. I am also grateful to the participants of the Albert O. Hirschman Seminar, the 2017 Max Weber Seminar, the 2018 Science and Energy Seminar, and the Young Scholars Seminar of the 2018 ESHET Conference. Finally, I want to thank two anonymous reviewers for their valuable remarks. However, all remaining shortcomings are mine.

\section{Disclosure Statement}

No potential conflict of interest was reported by the author.

\section{References}

Anderson, Curt L. 1987. "The Production Process: Inputs and Wastes." Journal of Environmental Economics and Management 14 (1): 1-12. 
Ayres, Robert U. 1997. "Comments on Georgescu-Roegen." Ecological Economics 22 (3): 285287.

Ayres, Robert U. 1999. "The Second Law, the Fourth Law, Recycling and Limits to Growth." Ecological Economics 29 (3): 473-483.

Ayres, Robert U. 2007. "On the Practical Limits to Substitution." Ecological Economics 61 (1): 115-128.

Baumgärtner, Stefan. 2004. "The Inada Conditions for Material Resource Inputs Reconsidered." Environmental \&3 Resource Economics 29 (3): 307-322.

Baumgärtner, Stefan, Christian Becker, Karin Frank, Birgit Müller, and Martin Quaas. 2008. "Relating the Philosophy and Practice of Ecological Economics: The Role of Concepts, Models, and Case Studies in Inter- and Transdisciplinary Sustainability Research." Ecological Economics 67 (3): 384-393.

Benchekroun, Hassan, and Cees Withagen. 2011. "The optimal depletion of exhaustible resources: A complete characterization." Resource and Energy Economics 33 (3): 612-636.

Bobulescu, Roxana. 2012. "The Making of a Schumpeterian Economist: Nicholas GeorgescuRoegen." European Journal of the History of Economic Thought 19 (4): 625-651.

Bobulescu, Roxana. 2013. "L'expérience roumaine et son influence sur la pensée de Nicolas Georgescu-Roegen." Economies et sociétés (10): 1753-1775.

Bobulescu, Roxana. 2015. "From Lotka's Biophysics to Georgescu-Roegen's Bioeconomics." Ecological Economics 120: 194-202.

Boianovsky, Mauro, and Kevin D. Hoover. 2009. "The Neoclassical Growth Model and Twentieth-Century Economics." History of Political Economy 41: 1-23.

Boulding, Kenneth E. 1966. "The Economics of the Coming Spaceship Earth." In Environmental Quality Issues in a Growing Economy, edited by Henry Jarrett, 3-14. Baltimore, MD: Johns Hopkins Press.

Brundtland, Gro Harlem. 1987. Our Common Future: Report of the World Commission on Environment and Development. Oxford: Oxford University Press.

Callen, Herbert B. 1985. Thermodynamics and an Introduction to Thermostatistics. 2nd ed. New York: John Wiley \& Sons.

Carnot, Sadi. 1824. Réflexions sur le puissance motrice du feu et sur les machines propres à développer cette puissance. Paris: Bachelier.

Castle, Emery N. 1997. "A Comment on Georgesu-Roegen, Daly, Solow and Stiglitz." Ecological Economics 22 (3): 305-306.

Christensen, Paul P. 1989. "Historical Roots for Ecological Economics — Biophysical versus Allocative Approaches." Ecological Economics 1 (1): 17-36.

Clark, Colin W. 1997. "Renewable Resources and Economic Growth." Ecological Economics 22 (3): $275-276$.

Cleveland, Cutler J., and Matthias Ruth. 1997. "When, Where, and by How Much Do Biophysical Limits Constrain the Economic Process? A Survey of Nicholas Georgescu-Roegen's Contribution to Ecological Economics." Ecological Economics 22 (3): 203-223.

Common, Mick. 1997. "Is Georgescu-Roegen versus Solow/Stiglitz the Important Point?" Ecological Economics 22 (3): 277-279.

Daly, Herman E. 1974. "The Economics of the Steady State." The American Economic Review 64 (2): 15-21.

Daly, Herman E. 1979. "Entropy, Growth, and the Political Economy of Scarcity." In Scarcity and Growth Reconsidered, edited by V. Kerry Smith, 67-94. New York: Resources for the Future Press.

Daly, Herman E. 1990. "Toward some Operational Principles of Sustainable Development." Ecological Economics 2 (1): 1-6.

Daly, Herman E. 1997a. "Georgescu-Roegen versus Solow/Stiglitz." Ecological Economics 22 (3): 261-266.

Daly, Herman E. 1997b. "Reply to Solow/Stiglitz." Ecological Economics 22 (3): 271-273.

Dasgupta, Partha S., and Geoffrey M. Heal. 1974. "The Optimal Depletion of Exhaustible Resources." The Review of Economic Studies 41: 3-28. 
Eddington, Arthur S. 1928. The Nature of the Physical World. Cambridge, UK: Cambridge University Press.

Erreygers, Guido. 2009. "Hotelling, Rawls, Solow: How Exhaustible Resources Came to Be Integrated into the Neoclassical Growth Model." History of Political Economy 41: 263-281.

Georgescu-Roegen, Nicholas. 1966. Analytical Economics: Issues and Problems. Cambridge, MA: Harvard University Press.

Georgescu-Roegen, Nicholas. 1971. The Entropy Law and the Economic Process. Cambridge, MA: Harvard University Press.

Georgescu-Roegen, Nicholas. 1975. "Energy and Economic Myths." Southern Economic Journal 41 (3): 347-381.

Georgescu-Roegen, Nicholas. 1976. Energy and Economic Myths: Institutional and Analytical Economic Essays. New York: Pergamon Press.

Georgescu-Roegen, Nicholas. 1977. "The Steady State and Ecological Salvation: A Thermodynamic Analysis." BioScience 27 (4): 266-270.

Georgescu-Roegen, Nicholas. 1979. "Comments on the Papers by Daly and Stiglitz." In Scarcity and Growth Reconsidered, edited by Kerry V. Smith, 95-105. New York: Resources for the Future Press.

Georgescu-Roegen, Nicholas. 1981. "The Crisis of Natural Resources." Challenge 24 (1): 50-56.

Georgescu-Roegen, Nicholas. 1986. "The Entropy Law and the Economic Process in Retrospect." Eastern Economic Journal 12 (1): 3-25.

Georgescu-Roegen, Nicholas. 1988. "Closing Remarks: About Economic Growth - A Variation on a Theme by David Hilbert." Economic Development and Cultural Change 36 (3): S291S307.

Georgescu-Roegen, Nicholas. 2011. "La dégradation entropique et la destinée prométhéenne de la technologie humaine." In La décroissance, 3rd ed. Paris: Sang de la Terre. Published for the first time in 1982, in Économie appliquée.

Gowdy, John, and Susan Mesner. 1998. "The Evolution of Georgescu-Roegen's Bioeconomics." Review of Social Economy 56 (2): 136-156.

Halsmayer, Verena. 2014. "From Exploratory Modeling to Technical Expertise: Solow's Growth Model as a Multipurpose Design." History of Political Economy 46: 229-251.

International Union for Conservation of Nature. 1980. World Conservation Strategy: Living Resource Conservation for Sustainable Development. Gland, Switzerland.

Klein, Julie Thompson. 2010. "A Taxonomy of Interdisciplinarity." In The Oxford Handbook of Interdisciplinarity, edited by Robert Frodeman, Julie Thompson Klein, and Carl Mitcham, 15-30. Oxford: Oxford University Press.

Krysiak, Frank C. 2006. "Entropy, Limits to Growth, and the Prospects for Weak Sustainability." Ecological Economics 58 (1): 182-191.

Kurz, Heinz D., and Neri Salvadori. 2003. "Fund-Flow versus Flow-Flow in Production Theory: Reflections on Georgescu-Roegen's Contribution." Journal of Economic Behavior \& Organization 51 (4): 487-505.

Levallois, Clément. 2010. "Can De-growth Be Considered a Policy Option? A Historical Note on Nicholas Georgescu-Roegen and the Club of Rome." Ecological Economics 69 (11): 2271 2278 .

Martinez-Alier, Juan. 1987. Ecological Economics: Energy, Environment and Society. Cambridge, MA: Basil Blackwell.

Mayumi, Kozo, Mario Giampietro, and John M. Gowdy. 1998. "Georgescu-Roegen/Daly versus Solow/Stiglitz Revisited." Ecological Economics 27 (2): 115-117.

Meadows, Donella H., Dennis L. Meadows, Jorgen Randers, and William W. Behrens. 1972. The Limits to Growth. New York: Universe Books.

Missemer, Antoine. 2013. Nicholas Georgescu-Roegen, pour une révolution bioéconomique. Lyon: ENS Éditions.

Missemer, Antoine. 2017a. Les Économistes et la fin des énergies fossiles (1865-1931). Paris: Classiques Garnier.

Missemer, Antoine. 2017b. "Nicholas Georgescu-Roegen and Degrowth." The European Journal 
of the History of Economic Thought 24 (3): 493-506.

Morgan, Mary S., and Margaret Morrison. 1999. "Models as Mediating Instruments." In Models as Mediators: Perspectives on Natural and Social Science, edited by Mary S. Morgan and Margaret Morrison, Vol. 52 of Ideas in Context, 10-37. Cambridge, UK: Cambridge University Press.

Neumayer, Eric. 2013. Weak versus Strong Sustainability: Exploring the Limits of Two Opposing Paradigms. 4th ed. Cheltenham, UK: Edward Elgar Publishing.

Nordhaus, William D., and James Tobin. 1972. "Is Growth Obsolete?" In Economic Growth, Vol. 5 of Economic Research: Retrospect and Prospect, 1-80. National Bureau of Economic Research.

Opschoor, J. B. 1997. "The Hope, Faith and Love of Neoclassical Environmental Economics." Ecological Economics 22 (3): 281-283.

Pearce, David. 1997. "Substitution and Sustainability: Some Reflections on GeorgescuRoegen." Ecological Economics 22 (3): 295-297.

Pearce, David. 2002. "An Intellectual History of Environmental Economics." Annual Review of Energy and the Environment 27 (1): 57-81.

Peet, John. 1997. "Georgescu-Roegen versus Solow/Stiglitz'...but What Is the Real Question?" Ecological Economics 22 (3): 293-294.

Perrings, Charles. 1997. "Georgescu-Roegen and the 'Irreversibility' of Material Processes." Ecological Economics 22 (3): 303-304.

Pezzey, John, and Michael A. Toman. 2005. "Sustainability and its Interpretations." In Scarcity and Growth Revisited : Natural Resources and the Environment in the New Millennium, edited by David Simpson, Michael A. Toman, and Robert Ayres. Washington, DC: Resources for the Future Press.

Pottier, Antonin. 2014. "L'économie dans l'impasse climatique. Développement matériel, théorie immatérielle et utopie auto-stabilisatrice." PhD diss., EHESS, Paris.

Røpke, Inge. 2004. "The Early History of Modern Ecological Economics." Ecological Economics 50 (3): 293-314.

Røpke, Inge. 2005. "Trends in the Development of Ecological Economics from the Late 1980s to the Early 2000s." Ecological Economics 55 (2): 262-290.

Solow, Robert M. 1956. "A Contribution to the Theory of Economic Growth." The Quarterly Journal of Economics 70 (1): 65-94.

Solow, Robert M. 1957. "Technical Change and the Aggregate Production Function." The Review of Economics and Statistics 39 (3): 312-320.

Solow, Robert M. 1973. "Is the End of the World at Hand?" Challenge 16 (1): 39-50. Accessed 2017-07-21. http://www.jstor.org/stable/40719094.

Solow, Robert M. 1974a. "The Economics of Resources or the Resources of Economics." The American Economic Review 64 (2): 1-14.

Solow, Robert M. 1974b. "Intergenerational Equity and Exhaustible Resources." The Review of Economic Studies 41: 29-45.

Solow, Robert M. 1978. "Resources and Economic Growth." The American Economist 22 (2): $5-11$.

Solow, Robert M. 1993. "An Almost Practical Step toward Sustainability." Resources Policy 19 (3): 162-172.

Solow, Robert M. 1997. "Georgescu-Roegen versus Solow-Stiglitz." Ecological Economics 22 (3): 267-268.

Solow, Robert M. 2009a. "An Amateur Among Professionals." Annual Review of Resource Economics 1 (1): 1-14.

Solow, Robert M. 2009b. "Does Growth Have a Future? Does Growth Theory Have a Future? Are These Questions Related?" History of Political Economy 41: 27-34.

Solow, Robert M., and Frederic Y. Wan. 1976. "Extraction Costs in the Theory of Exhaustible Resources." The Bell Journal of Economics 7 (2): 359-370.

Spash, Clive. 1999. "The Development of Environmental Thinking in Economics." Environmental Values 8 (4): 413-435. 
Spash, Clive L. 2012. "New Foundations for Ecological Economics." Ecological Economics 77: $36-47$.

Stiglitz, Joseph E. 1974. "Growth with Exhaustible Natural Resources: Efficient and Optimal Growth Paths." The Review of Economic Studies 41: 123-137.

Stiglitz, Joseph E. 1976. "Monopoly and the Rate of Extraction of Exhaustible Resources." The American Economic Review 66 (4): 655-661.

Stiglitz, Joseph E. 1979. "A Neoclassical Analysis of the Economics of Natural Resources." In Scarcity and Growth Reconsidered, edited by Kerry V. Smith, 36-66. New York: Resources for the Future Press.

Stiglitz, Joseph E. 1997. "Georgescu-Roegen versus Solow/Stiglitz." Ecological Economics 22 (3): $269-270$.

Tisdell, Clem. 1997. "Capital/Natural Resource Substitution: The Debate of GeorgescuRoegen (through Daly) with Solow/Stiglitz." Ecological Economics 22 (3): 289-291.

Turner, Kerry R. 1997. "Georgescu-Roegen versus Solow/Stiglitz: A Pluralistic and Interdisciplinary Perspective." Ecological Economics 22 (3): 299-302.

van den Bergh, Jeroen C. J. M. 1999. "Materials, Capital, Direct/Indirect Substitution, and Mass Balance Production Functions." Land Economics 75 (4): 547-561.

Victor, Peter A. 1991. "Indicators of Sustainable Development: Some Lessons from Capital Theory." Ecological Economics 4 (3): 191-213.

Vittucci Marzetti, Giuseppe. 2013. "The Fund-Flow Approach: A Critical Survey." Journal of Economic Surveys 27 (2): 209-233. 